Article

\title{
The Impact of Air Pressure Conditions on the Performance of Single Room Ventilation Units in Multi-Story Buildings
}

\author{
Alo Mikola *, Raimo Simson (D) and Jarek Kurnitski \\ Nearly Zero Energy Research Group, Tallinn University of Technology, Tallinn 19086, Estonia \\ * Correspondence: alo.mikola@taltech.ee; Tel.: +372-566-47-035
}

Received: 30 April 2019; Accepted: 27 June 2019; Published: 9 July 2019

\begin{abstract}
Single room ventilation units with heat recovery is one of the ventilation solutions that have been used in renovated residential buildings in Estonia. In multi-story buildings, especially in a cold climate, the performance of units is affected by the stack effect and wind-induced pressure differences between the indoor and the outdoor air. Renovation of the building envelope improves air tightness and the impact of the pressure conditions is amplified. The aim of this study was to predict the air pressure conditions in typical renovated multi-story apartment buildings and to analyze the performance of room-based ventilation units. The field measurements of air pressure differences in a renovated 5-story apartment building during the winter season were conducted and the results were used to simulate whole-year pressure conditions with IDA-ICE software. Performance of two types of single room ventilation units were measured in the laboratory and their suitability as ventilation renovation solutions was assessed with simulations. The results show that one unit stopped its operation as a heat recovery ventilator. In order to ensure satisfactory indoor climate and heat recovery using wall mounted units the pressure difference values were determined and proposed for correct design.
\end{abstract}

Keywords: single room ventilation unit; building pressure condition; stack effect; wind pressure; ventilation renovation; decentralized ventilation unit

\section{Introduction}

In Estonia, multi-story apartment buildings constitute about $60 \%$ of the whole dwelling stock, and the majority (75\%) of the buildings were built primarily in 1961-1990 [1]. Due to the increase in the price of energy, the energy policies of the European Union [2], the age, construction quality, and poor thermal insulation of the buildings, as well as both morally and technically outdated, obsolete heating and ventilation systems, there is an increasing need for retrofitting [3-7]. Part of the building stock built before the 1990s has already been renovated but for many apartment buildings this process is yet to start $[6,8]$.

Typical multi-story apartment buildings have been built with natural ventilation, where fresh outdoor air enters through leaks or openings of the windows and doors, mixes with the warm room air, and leaves the building through shafts in the bathroom and kitchen. With retrofitting the building envelope, in order to achieve necessary thermal insulation for reducing the energy consumption for space heating, the air tightness of the building increases and the air flow through cracks and leaks is reduced, which makes the air change with natural ventilation very poor and does not provide the required air change rate [9]. Several analyses on the performance of ventilation in old Estonian dwellings $[3,4,8]$ show that average indoor air $\mathrm{CO}_{2}$ in occupied period is $1225 \mathrm{ppm}$ which means the air change rate is too low to ensure good indoor air quality. As concluded in previous 
studies [10-16], there is a strong correlation between ventilation and health. With the renovation of old apartment buildings, the improvement of ventilation is unavoidable in order to provide healthy indoor environment for the occupants [17].

During the period 2010 to 2014 a total number of 663 apartment buildings were renovated using the renovation grant scheme [18]. The main principle of this grant schemes was to improve indoor air climate and energy efficiency of Estonian apartment buildings. There were 3 different grant levels, but in order to qualify for the highest financial support of 35\% of the renovation costs provided by the state, the designed ventilation system was required to include heat recovery. Few solutions used in new buildings are suited for retrofitting purposes, mainly for construction-technological reasons. Other factors that affect the choice of suitable system are the cost of the system, the volume of construction work, aesthetics, adjustability and the costs of maintenance and operation. The impact of ventilation on the energy use of buildings can be between $30-60 \%$ for new and retrofitted buildings [5,8,19], thus heat recovery from the exhaust air is inevitable. Depending on the type of the heat exchanger (HEX) used in the air handling unit (AHU), it is possible to recover either sensible and latent heat or only sensible heat from the exhaust air $[20,21]$.

The need for electricity to move the air increases at higher ventilation rates, becoming in some cases the main factor of increase in the final energy demand [22-24]. Ductless systems with room-based air handling units tend to have the lowest construction and operation costs, and to be simplest in design and most aesthetic [25]. The lack of ducts is a clear advantage since the most common problems are caused by the poor installation quality of ducts and inadequate project design [4]. It is also essential for the ventilation unit to have a low electric power consumption, suitable acoustic properties [26] and sufficient energy saving performance, which is strongly related to outdoor climatic conditions, the enthalpy efficiency, fan power consumption and necessary fresh air change rate [27].

One way to save energy from grid-connected electrical appliances would also be a real-time control strategy based on Model Predictive Control for the energy scheduling [28]. Chen et al. have presented the development of a model predictive control strategy for the hybrid ventilation solution [29]. As this model is still a prototype, it needs more testing to analyze the detailed possibilities of Model Predictive Control strategies.

The two most commonly used types of room-based devices used to renovate ventilation systems of apartment buildings during the retrofits 2010-2014 are: unit with recuperative plate HEX and centrifugal fans (Figure 1a) and unit with regenerative ceramic HEX and an axial fan (Figure 1b). The single-fan-based unit works in cycles, switching between the supply and exhaust mode every 60-70 s. During the exhaust cycle, the heat from the warm exhaust air is accumulated in the ceramic comb-like HEX and is then used to heat up the cold outdoor air during the supply cycle.

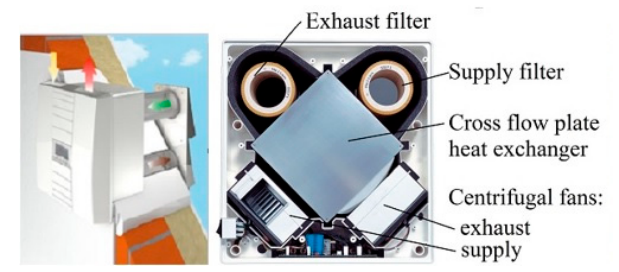

(a)
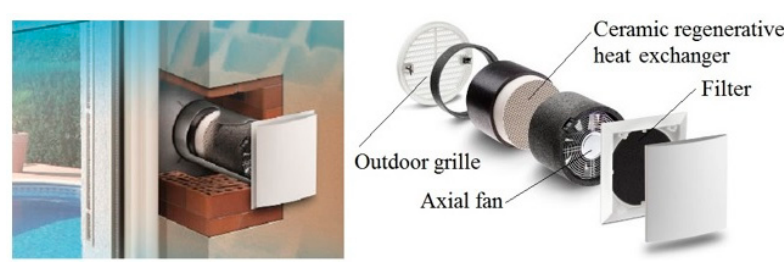

(b)

Figure 1. Types of room-based ventilation units used in the renovation of old apartment buildings: (a) with recuperative cross-flow plate HEX and (b) with regenerative ceramic heat exchanger (HEX).

Since the ventilation units are mounted inside the exterior wall of the building, the performance of the units is directly affected by the pressure differences between indoor and outdoor air across the building envelope. During the ventilation renovation in 2010-2014, the natural exhaust ventilation system was often not replaced. It means that the room-based ventilation units had to operate together with the natural ventilation system. The pressure difference in buildings with natural ventilation is caused mainly by the wind and the stack effect. There are numerous studies on both the stack 
effect [30-34] and the wind-induced pressure [35-37] in different building types with variable height, geometry and location. Wind conditions depend on the location and surroundings of the building. The stack effect depends on the height of the building and the temperature difference between indoor and outdoor air. The temperature differences of the air cause density differences that induce buoyancy force; the warm indoor air rises and is replaced by the colder outdoor air through the building envelope during the heating season. Studies indicate larger air pressure difference over the building envelope in more airtight buildings $[19,38]$. Shafts, staircases and other vertical openings, but also leaks through the cracks in floors, walls and ceilings can contribute considerably to the stack effect [39].

Indoor air quality measurements in Estonian renovated apartment buildings have shown that room-based ventilation units are not ensuring the necessary air change rate $[18,40]$. To secure the success of the renovation work, it is necessary to find out the reasons why the air change rate is below the designed values. Based on the described practical need, the main aim of this study is to analyze the performance of room-based ventilation units in typical renovated multi-story apartment buildings. Mikola et al. [40] have measured the air change rate in apartment buildings with room-based ventilation units and pointed out that problem may be caused by the high indoor and outdoor pressure difference and incorrect dimensioning of the fans. Thus, present study allows a detailed examination of these hypotheses. The results of the study can provide an innovative overview of the performance of the room-based ventilation units in renovated apartment buildings.

\section{Methods}

The performance of the exterior wall mounted single room ventilation units with regenerative and recuperative HEX were studied. Firstly, the on-site measurements were made in a renovated five-story apartment building. In next step, the measurements of units with regenerative HEX and recuperative HEX were performed in laboratory conditions. The results of field and laboratory measurements were used to compile a simulation model of the studied renovated apartment building with regenerative ventilation units. The next step was to calibrate the simulation model according to the measured indoor-and outdoor pressure differences, indoor temperatures, airflows, and outdoor climate data. Then the simulations of indoor and outdoor pressure differences, fan performance curves and heat recovery were performed. Lastly, the simulation and measurement results of room-based AHUs were analyzed and the conclusions on the performance of room-based ventilation units in apartment buildings were outlined. The flow chart of the main methods of the study is described in Figure 2.

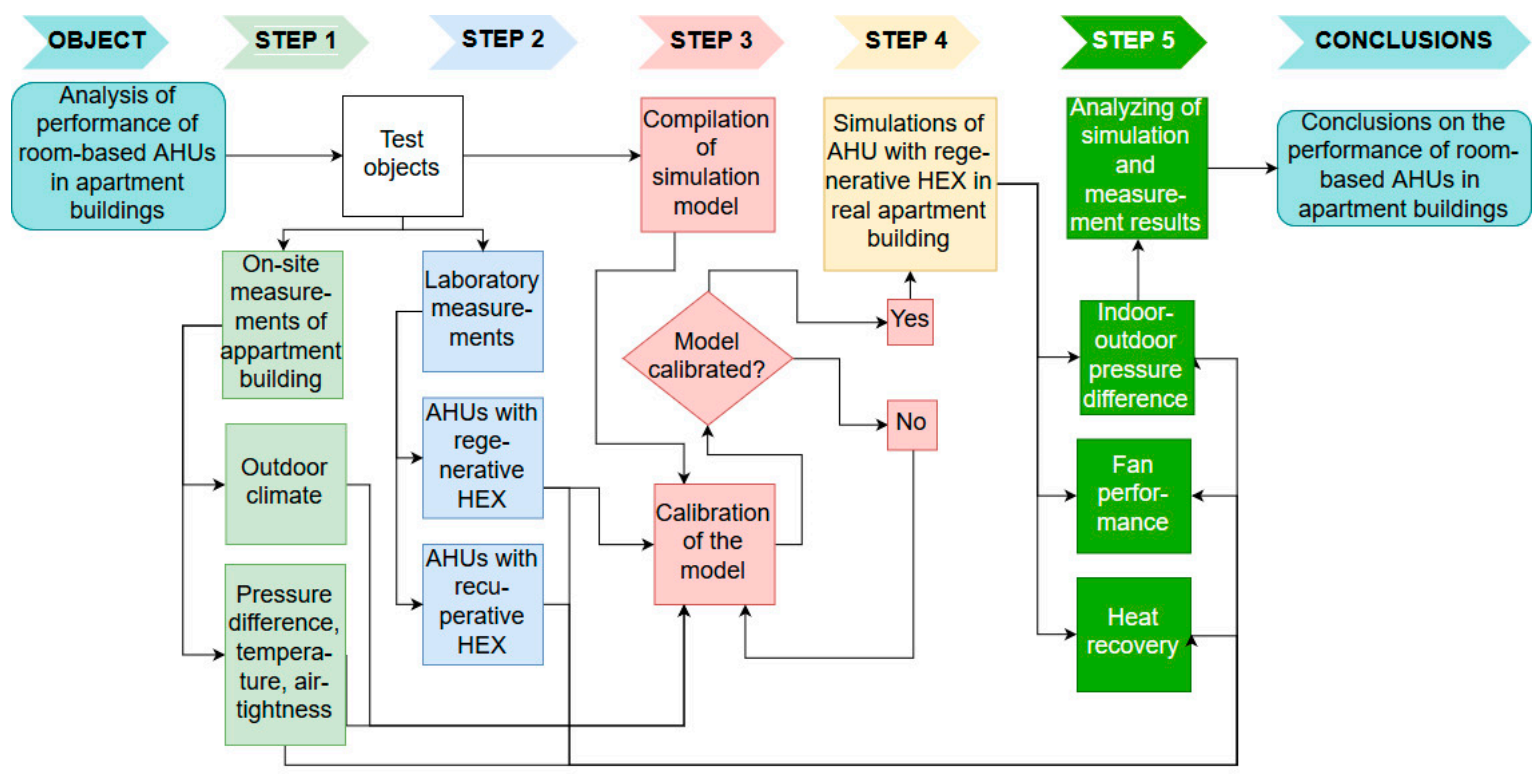

Figure 2. The flow chart of the performed studies. AHU: air handling unit. 


\subsection{Measurements}

The pressure differences between the indoor and outdoor air across the exterior wall were measured during a 3-month period of the heating season in renovated 5-story apartment building. The fan performance and the temperature efficiency of room-based ventilation unit with regenerative and recuperative HEX were studied in TalTech technological facility.

\subsubsection{The Studied Building}

The studied building was a typical precast large concrete panel 5-story apartment building located in an urban area built in 1975 with 30 apartments, 2 staircases and a full cellar. The building is connected on both sides with two buildings of the same type. The height of stories is $2.7 \mathrm{~m}$ and the height of rooms is $2.5 \mathrm{~m}$. The building is heated with water radiators by district heating. The floor plan of the building is shown in Figure $3 a$ and cross-section in Figure $3 b$.

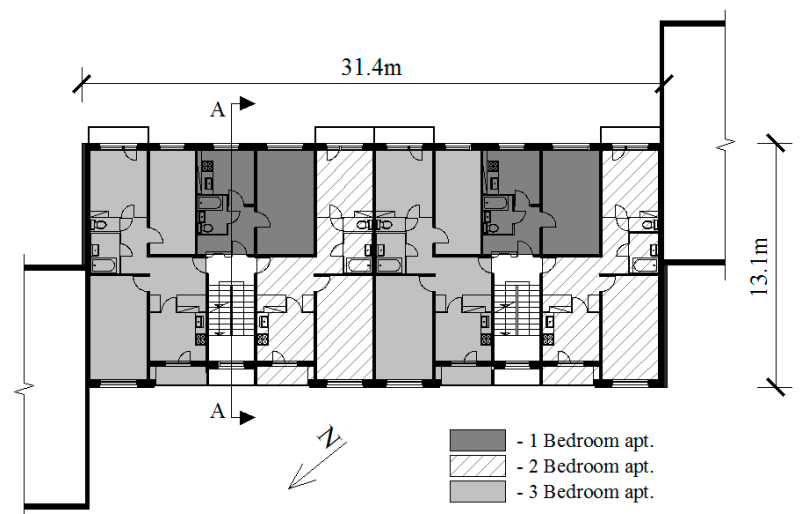

(a)

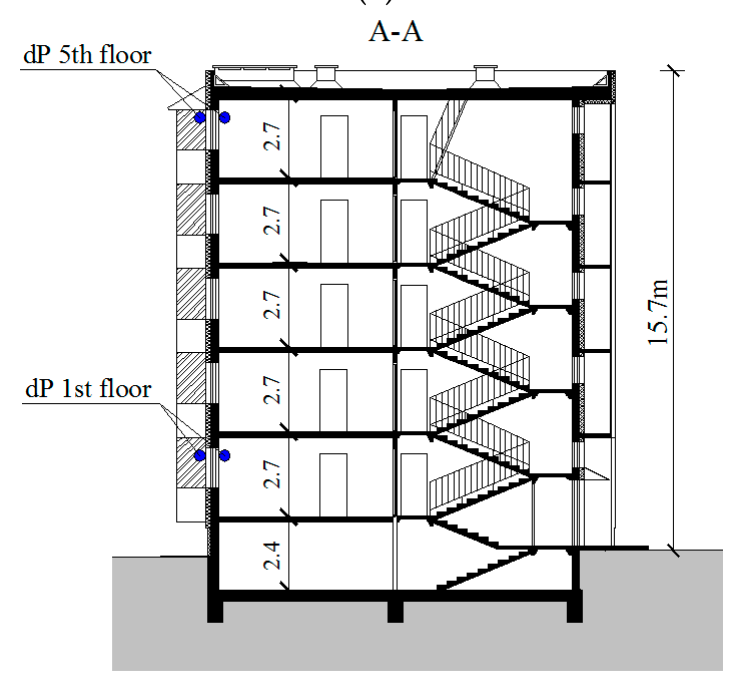

(b)

Figure 3. (a) Floor plan and (b) cross-section with pressure difference measurement point locations of the studied building.

The building was renovated in the years 2003 and 2012: the exterior walls, roof, and balconies were insulated, the windows were replaced; and the heating system was reconstructed. The thermal transmittances of the envelope before and after the retrofitting are presented in the Table 1 . For ventilation, wall mounted regenerative HEX ventilation units were installed in the bedrooms and living rooms, in the bathrooms and kitchens natural exhaust ventilation was used (Figure 4). The diameter of the ventilation shafts with round cross-sections is $140 \mathrm{~mm}$ and height varies between 
$0.7 \mathrm{~m}$ and $12.6 \mathrm{~m}$, depending on the story. All the units with regenerative HEX were controlled from the control center. It means that all the units worked in same speed and in same working cycle.

Table 1. Thermal transmittances of the envelope before and after retrofitting.

\begin{tabular}{ccc}
\hline \multirow{2}{*}{ Part of the Thermal Envelope } & \multicolumn{2}{c}{ Thermal Transmittance, $\mathbf{W} /\left(\mathbf{m}^{2} \cdot \mathbf{K}\right)$} \\
\cline { 2 - 3 } & Before & After \\
\hline External walls & 1.05 & 0.22 \\
Roof & 0.45 & 0.15 \\
Doors & 2.0 & 1.2 \\
Windows & 2.9 & 1.4 \\
\hline
\end{tabular}

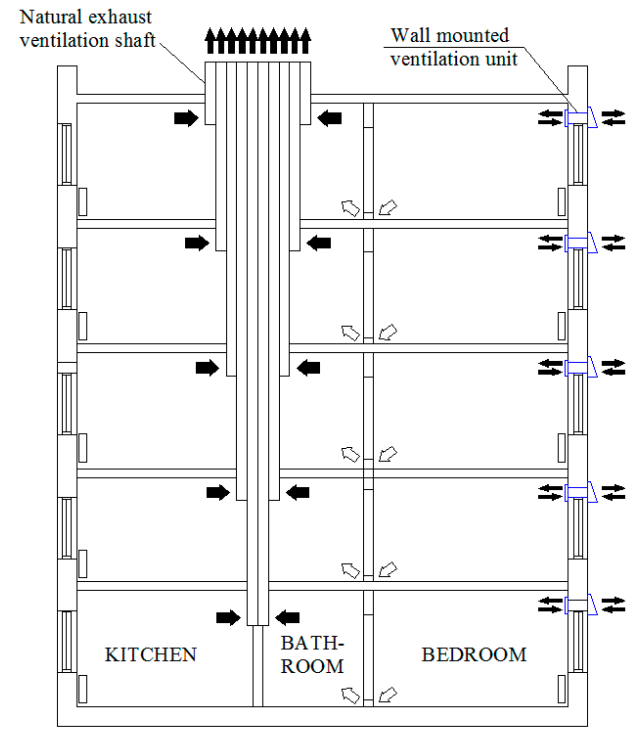

(a)

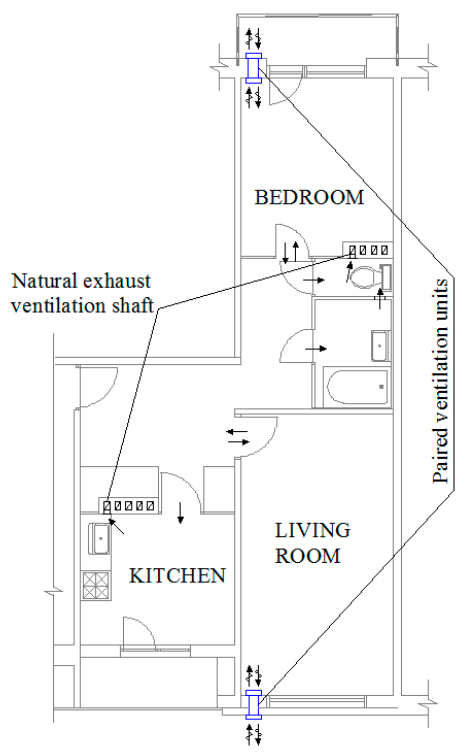

(b)

Figure 4. Principle solution of the ventilation system with room-based units: (a) cross-section and (b) floor plan of a typical apartment.

\subsubsection{Field Measurements}

Pressure differences between the indoor and outdoor air across the exterior wall were measured during a 3-month period of the heating season (December 2013-February 2014) in 4 apartments located on different floors. Measurements were taken at the height of $2 \mathrm{~m}$ from the floor level (Figure $3 \mathrm{~b}$ ). For the outdoor pressure component, a plastic tube of $4 \mathrm{~mm}$ in diameter was planted through the window seal with one end connected to the pressure transducer. Diaphragm-type pressure transducers were used: Dwyer Magnesense MS-221 and Onset T-VER-PXU-L both with the measuring range of -50 to $+50 \mathrm{~Pa}$ (output $0-10$ VDC) and accuracy of $1 \%$ full scale output. Readings were taken in every $1 \mathrm{~min}$ and an average of the readings was saved with a 10-min interval using Onset Hobo U12 and Squirrel Q2010 data loggers. For environment measurements and data logging Hobo U12 devices were used with the temperature measuring range of -20 to $+70{ }^{\circ} \mathrm{C}$ with accuracy $\pm 0.35^{\circ} \mathrm{C}$ and relative humidity $5 \%$ to $95 \%$ with accuracy $\pm 2.5 \%$ of full-scale output.

\subsubsection{Laboratory Measurements}

In the laboratory-controlled environment, performance and efficiency of two types of room-based ventilation units were studied. The core elements of the first unit are cross-flow plate HEX, centrifugal fan, supply and exhaust filters, transfer ducts and outdoor hoods (see Figure 1a). The second unit has a ceramic HEX, axial fan, mounting tube, outdoor hood, inner cover and air filter (see Figure 1b). 
The first device is a constant flow ventilation unit compared to the latter, which works in cycles, switching with 70-s intervals between the supply and exhaust mode. During the exhaust cycle, heat from the warm exhaust air is accumulated in the ceramic comb and is then used to heat up the cold outdoor air during the supply cycle. Both devices are installed without the heating coil.

The setup of the experiment of recuperative units is shown in Figure 5a and setup of the regenerative HEX is shown in Figure 5b. In the case of the unit with regenerative HEX, the temperature sensor was placed in the center of the airflow behind the air distributor. To measure the room and exhaust air temperature, another temperature sensor was placed to the top of the room $0.3 \mathrm{~m}$ away from the ventilation unit. The outdoor air temperature was measured close to the fresh air grille. The measuring cone was placed over the inner cap of the unit and the air speed was measured inside the cone. To measure the outside pressure, the pressure sensor was installed through the window to outside. The inside and outside pressure were both measured at a height of two meters. In case of unit with recuperative HEX, the temperature sensors were installed on the top of the unit inside the supply and exhaust airflow. The airflow, fresh air temperature, and pressure difference were measured in the same way as described in case of unit with regenerative HEX.

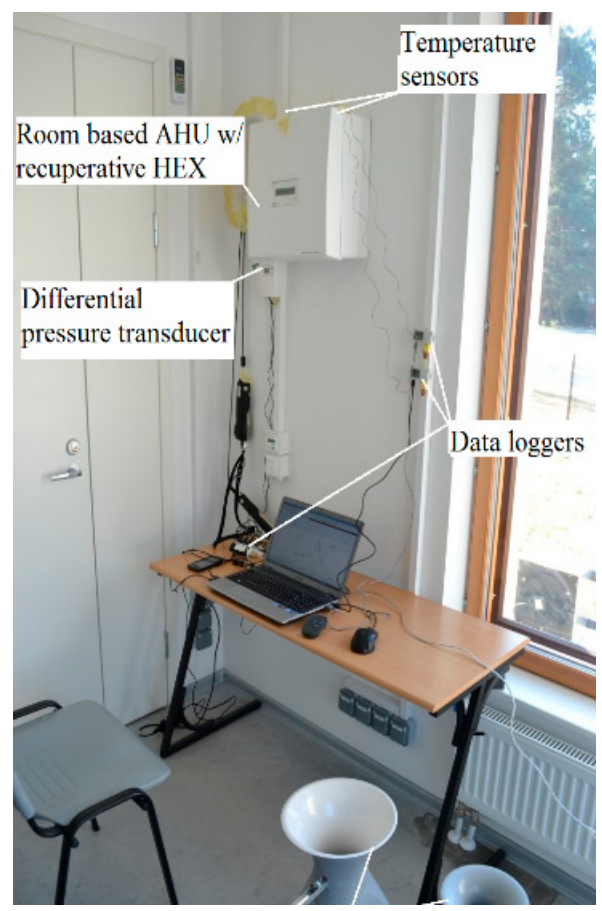

(a)

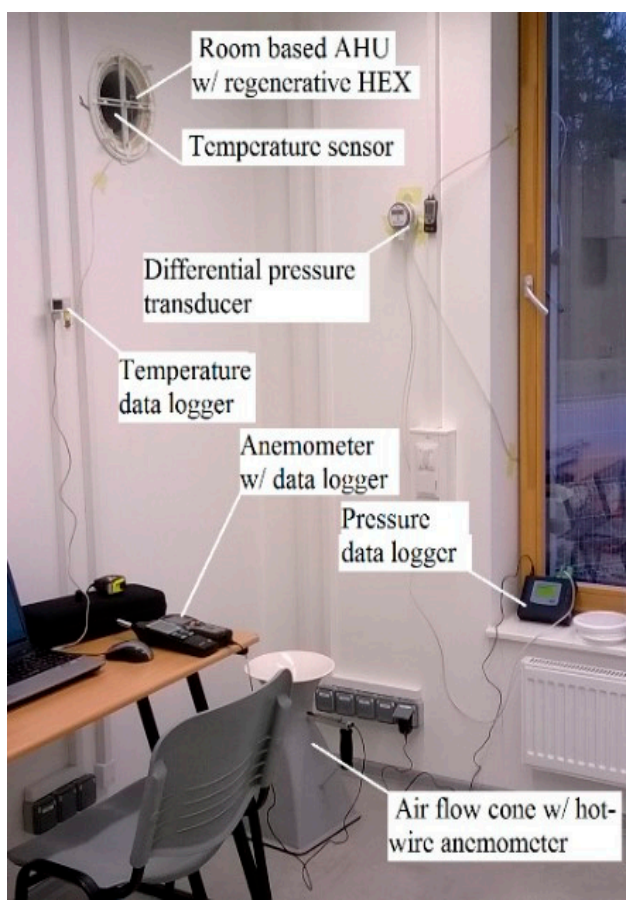

(b)

Figure 5. Experimental setup with the studied room-based ventilation units: (a) with recuperative HEX and $(\mathbf{b})$ regenerative HEX.

During the experiments, the pressure difference between the indoor and outdoor air, outdoor temperature, supply/exhaust air temperature and air speed inside the measuring cone were measured and logged in every second. The same temperature and pressure sensors and loggers were used as in field measurements. The measured air speed was used to calculate the volumetric air flow through the unit. Airflow measurements were carried out using Testo 435-4 measuring instrument/data logger with hot-wire anemometry probe (measuring range from 0 to $20 \mathrm{~m} / \mathrm{s}$, with accuracy $0.01 \mathrm{~m} / \mathrm{s}$ and $+4 \%$ of reading). The pressure conditions in the test room were achieved using a central air handling unit and by adjusting the supply/exhaust valves of the ventilation system. 


\subsubsection{Temperature Efficiency of Room-Based Units}

The temperature efficiency was used to quantify the effect of heat recovery of the studied ventilation system. As the main purpose of the study is to evaluate the performance of the room-based ventilation units, then the temperature ratio (efficiency) $\eta_{\text {temp }}$ is defined as $[25,26]$ :

$$
\eta_{\text {temp }}=\frac{\overline{t_{\text {sup }}}-t_{\text {out }}}{t_{\text {exh }}-t_{\text {out }}}
$$

where $t_{\text {out }}$ is the outdoor air temperature and $t_{\text {exh }}$ is the exhaust air temperature. The time-averaged value of the supply air temperature of ventilation units with the regenerative HEX, has to be used which is given by [26]:

$$
\overline{t_{\text {sup }}}=\frac{1}{\tau} \int_{t=0}^{t=\tau} t_{\text {sup }}(t) \cdot d t
$$

where $t$ is the time and $\tau$ is the semi-period, which means the duration of the supply or extract process. In the case of the recuperative HEX, the process is in a steady state [26]:

$$
t_{\text {sup }}(t)=\text { const. }
$$

\subsection{Computational Model}

\subsubsection{Description of Simulation Model}

A model of the building was created and simulated using IDA Indoor Climate and Energy (IDA ICE) software version 4.6 developed by Equa Simulation AB (Figure 6). Each room of the composed building model is the separate zone. As there is common natural ventilation exhaust channel for the bathroom and toilet, these rooms were composed as a one zone. The building model was calibrated using the measured data from field studies. A custom climate file with hourly wind data, outdoor temperature and relative humidity of the measurement period from the local weather station located $\sim 1 \mathrm{~km}$ from the site was used for the validation process. The orientation of the building is presented in Figure 3a.

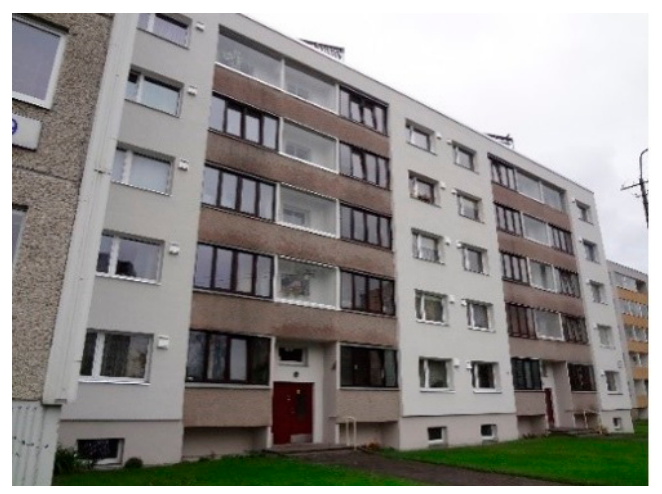

(a)

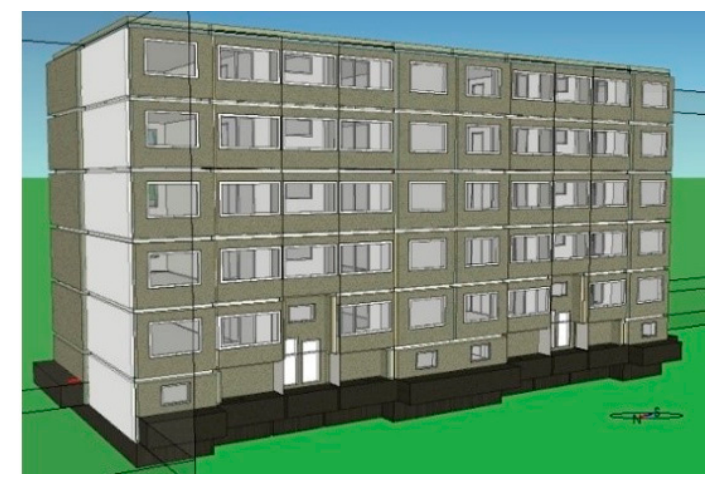

(b)

Figure 6. The studied (a) apartment building and (b) the simulation model.

For whole-year simulation, weather data from Estonian Test Reference Year (TRY) were used. The TRY is constructed using selected months from a number of calendar years, and may be used for many applications, such as indoor climate and energy simulations, HVAC system performance, or simulation of active or passive solar energy systems [41]. The air tightness of the building was defined with air leakage rate per envelope area at $50 \mathrm{~Pa}$ of pressure difference $\left(\mathrm{q}_{50}\right)$. A value of 3.0 $\mathrm{m}^{3} /\left(\mathrm{h} \cdot \mathrm{m}^{2}\right)$ was used in the calibration process, as also achievable with the renovation of building envelope for pre-fabricated large-panel buildings [42]. 
The ventilation units were inserted according to the standard renovation solution that means 1 pair-wise ventilation system, which consist of 2 separate units, was added in every living room and bedroom. The natural exhaust ventilation system was not renovated and it continued the work as before. To modulate the natural ventilation system, the "chimney" component was used. Chimney takes into account the height and length of ventilation channels but also friction and minor pressure losses. Chimney elements were added to the kitchens and toilets or bathrooms. Two chimney components were added per each apartment. The airflows of natural exhaust systems were measured using hot wire anemometer with a cone. During the air flow measurements, the specific indoor and outdoor parameters were also measured and for the model calibration average values of airflow measurements were used.

The studied ventilation unit with regenerative HEX was modelled using IDA-ICE advanced modelling interface. The exterior wall leak module was used to calculate the differential pressure across the building exterior wall, which was used as an input for supply and exhaust air flow control accordingly to the laboratory measurements results. The main principles of the model are described in Figure 7. The pressure-airflow dependencies were inserted to the linear segment controller and connected to the respective air terminal. To model room-based units, some simplifications were made. Firstly, the standard ventilation unit macro was used and the control signal to the HEX was removed. The working cycle of the unit is $60 \mathrm{~s}$ in supply mode and after that the unit is turned off and the pairing device is switched on for $60 \mathrm{~s}$ in exhaust mode. Switching the units between supply and exhaust mode is achieved using the "gain" component. Regulating the supply and exhaust airflow was performed according to the differential pressure variable (DPA_S) of the exterior wall in "leak" component.

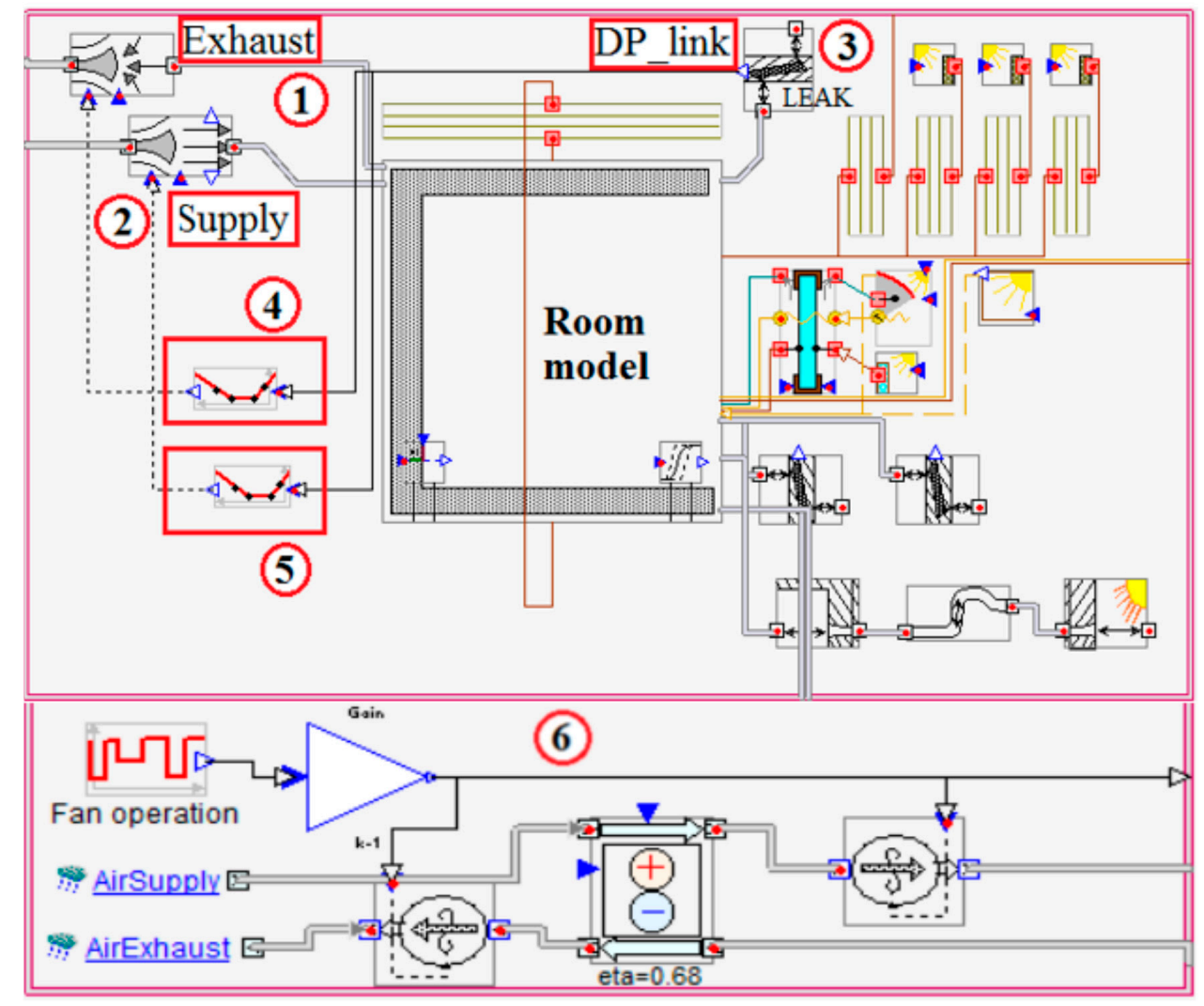

Figure 7. Schematics of the studied ventilation units modelling in IDA Indoor Climate and Energy (IDA ICE): (1) exhaust air terminal; (2) supply air terminal; (3) exterior wall leak module; (4) and (5) linear segment controllers; (6) ventilation unit module. 


\subsubsection{Air Pressure Calculations}

The simulation model was calibrated according to the outdoor climate, indoor temperature, air change rate and air tightness measurements. During the calibration, the values of measured pressure difference were compared to the simulated data. The wind pressure distribution around the house is composed in way the wind flow is horizontal and an atmospheric boundary layer is neutral without vertical airflow [19]. The static wind pressure $\mathrm{p}_{\text {wind }}(\mathrm{Pa})$ outside the building facades is given by $[19,43]$ :

$$
\mathrm{p}_{\text {wind }}=\mathrm{C}_{\mathrm{p}} \cdot \varrho_{\mathrm{a}} \cdot \mathrm{U}^{2} / 2
$$

where $C_{p}$ (dimensionless) is the pressure coefficient, $\varrho_{a}$ is the air density $\left(\mathrm{kg} / \mathrm{m}^{3}\right)$ and $U(\mathrm{~m} / \mathrm{s})$ is the local wind velocity.

Pressure coefficients are empirically derived parameters determined either experimentally in a wind tunnel $[44,45]$ or numerically using computational fluid dynamics [46,47]. In studied building model the wind-induced pressure conditions were simulated using constant wind-pressure coefficients defined at $45^{\circ}$ intervals of a wind direction. Approximate values of wind pressure coefficients were used on external boundaries based on the exposure of the building. The pre-coded values of the "semi-exposed" option founded accurate enough (see Table 2).

Table 2. Facade average wind pressure coefficients used in the building simulation.

\begin{tabular}{lccccccccc}
\hline \multirow{2}{*}{ Facade } & \multirow{2}{*}{ Orientation } & \multicolumn{7}{c}{ Wind Angle ( ${ }^{\circ}$ ) } \\
\cline { 3 - 10 } & & $\mathbf{0}$ & $\mathbf{4 5}$ & $\mathbf{9 0}$ & $\mathbf{1 3 5}$ & $\mathbf{1 8 0}$ & $\mathbf{2 2 5}$ & $\mathbf{2 7 0}$ & $\mathbf{3 1 5}$ \\
\hline Exterior wall & $\mathrm{NE}$ & 0.4 & 0.2 & -0.6 & -0.5 & -0.3 & -0.5 & -0.6 & 0.2 \\
Exterior wall & $\mathrm{SE}$ & 0.25 & 0.06 & -0.35 & -0.6 & -0.5 & -0.6 & -0.35 & 0.06 \\
Exterior wall & $\mathrm{SW}$ & 0.4 & 0.2 & -0.6 & -0.5 & -0.3 & -0.5 & -0.6 & 0.2 \\
Exterior wall & $\mathrm{NW}$ & 0.4 & 0.2 & -0.6 & -0.5 & -0.3 & -0.5 & -0.6 & 0.2 \\
$\quad$ Roof & & -0.8 & -0.8 & -0.8 & -0.8 & -0.8 & -0.8 & -0.8 & -0.8 \\
\hline
\end{tabular}

The local wind velocity is calculated according to the simplified method for combining weather information with air tightness to calculate residential air infiltration (LBL method) recommended by American Society of Heating, Refrigerating and Air-Conditioning Engineers (ASHRAE) [43]. The local wind velocity at height $\mathrm{h} \mathrm{U}(\mathrm{h})(\mathrm{m} / \mathrm{s})$ is calculated by the equation:

$$
\mathrm{U}(\mathrm{h})=\mathrm{U}_{\mathrm{m}} \cdot \mathrm{k} \cdot\left(\mathrm{h} / \mathrm{h}_{\mathrm{m}}\right)^{\mathrm{a}}
$$

where $U_{m}(m / s)$ is the measured wind speed at the weather station (at a height of $\left.10 \mathrm{~m}\right), \mathrm{h}(\mathrm{m})$ the height from the surface of the ground, $h_{m}(m)$ the height of the measurement equipment and constants $k$ and $a$ are the terrain coefficients. For the terrain coefficients $k$ and a ASHRAE [43] recommended values for suburban terrain of 0.67 and 0.25 respectively were used. The LBL method, that is used in simulation model, has been proposed by Sherman and Grimsrud [48] and Modera et al. [49]. Modera et al. [49] have pointed out the typical values of terrain parameters for the standard terrain classes. The IV class is described as urban, industrial or forest areas and fitted the best with the conditions of tested apartment building. Sherman and Grimsrud [48] have pointed out that this method can also be used when the wind speed was not measured on-site.

The airflow $\mathrm{Q}(\mathrm{kg} / \mathrm{s})$ through the bi-directional leakage opening is simulated in the building model with the empirical power law equation [19]:

$$
\mathrm{Q}=\mathrm{C} \cdot \Delta \mathrm{P}^{\mathrm{n}},
$$

where $\mathrm{C}$ (dimensionless) is a flow coefficient (related to the opening), $\Delta \mathrm{P}(\mathrm{Pa})$ is the pressure difference over the opening and $\mathrm{n}$ is a flow exponent which is characterizing the flow regime. The infiltration air 
flow is calculated for the facade of every zone [19]. The leakage openings in model are distributed over the building model according to the total infiltration airflow.

\section{Results}

\subsection{Field Measurements}

The results of field measurements showed that the pressure difference across the building envelope was negative during the entire measurement period in the first floor apartment and mostly negative in the fifth floor apartment (see Figure 8a). The occasional peaks toward zero-pressure difference are most likely caused by using the cooker hood, opening the windows or external doors to the balcony or staircase, the peaks and periods toward greater difference indicate the wind-induced effect. Pressure difference caused by wind can be dominant also for longer periods. The results indicate that the pressure difference is mostly caused by the stack effect being strongly dependent on the outdoor temperature in the bottom floor apartment, whereas on the top floor the dependence is weak due to the smaller height of the shaft (see Figure 8a). The measured indoor temperature during the measurement period in both apartments was roughly between 20 and $22{ }^{\circ} \mathrm{C}$. The dependence between the indoor and outdoor pressure and temperature is shown in Figure $8 \mathrm{~b}$. In the first-floor apartment the value of linear correlation coefficient $R^{2}$ is 0.7483 and in fifth floor 0.0281 .

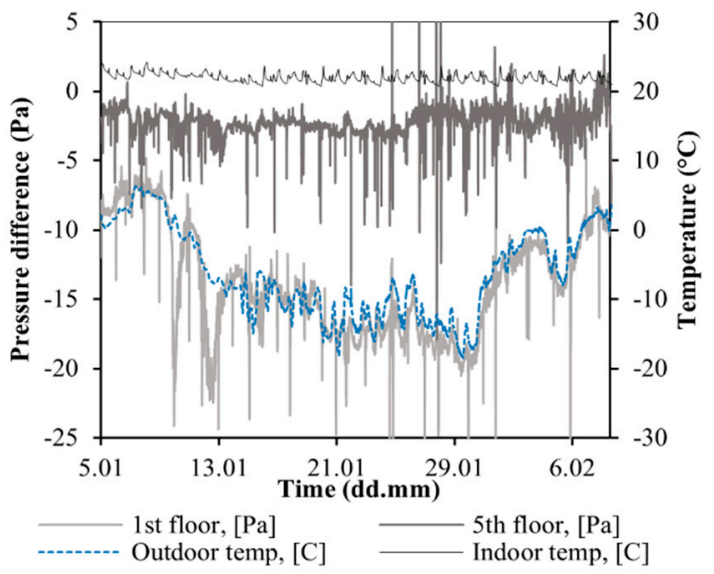

(a)

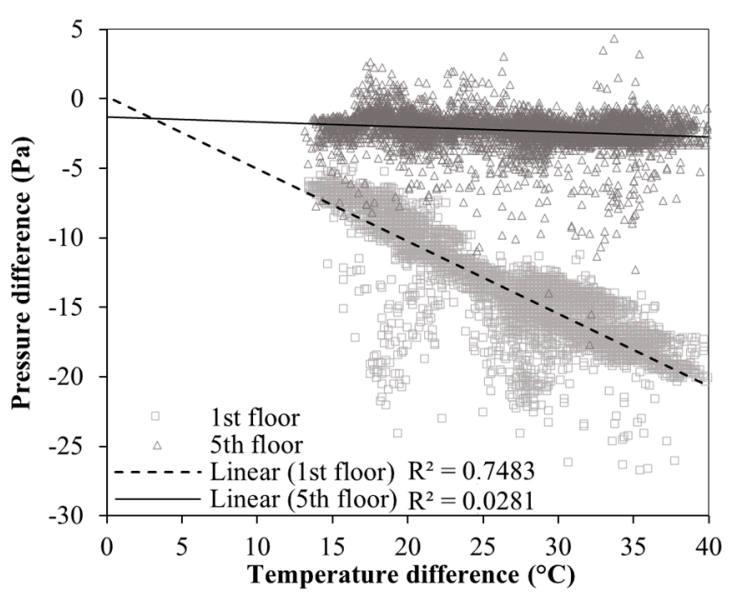

(b)

Figure 8. (a) The measured indoor and outdoor pressure differences in the first and fifth floor apartments, indoor and outdoor temperature in the heating season during a one-month period; (b) The dependence of pressure conditions on the indoor-outdoor temperature difference.

\subsection{The Laboratory Measurements}

Based on the results of laboratory measurements the fan performance and HEX temperature efficiency of observed AHUs were studied. The measurement results of the performance of the unit with ceramic HEX are shown in Figure 9a,b. In the beginning of the tests the value of underpressure in room was $-2 \mathrm{~Pa}$ which means that supply and extract airflows were equal. After the pressure difference increased the extract air flow decreased and supply airflow increased at the same time. As results indicate, the supply and extract airflows are equal only at very low pressure differences. The greater the difference, the more the air flows differ. It can be seen that in case of $75 \%$ fan power, with differential pressure over $-20 \mathrm{~Pa}$ the extract airflow is close to zero and the supply airflow around $60 \mathrm{~m}^{3} / \mathrm{h}$ (Figure 9b). The supply-exhaust cycles, which are presented in Figure 9b, show quick drop of the supply air temperature after the cycle change. During the tests, the outdoor air temperature was close to $-5^{\circ} \mathrm{C}$. If the supply and extract airflows are equal, the supply air temperature was about $7{ }^{\circ} \mathrm{C}$ but if the pressure difference was increased from $0 \mathrm{~Pa}-20 \mathrm{~Pa}$ in test room, the supply air temperature at the end of the supply working cycle was about $-2{ }^{\circ} \mathrm{C}$. 


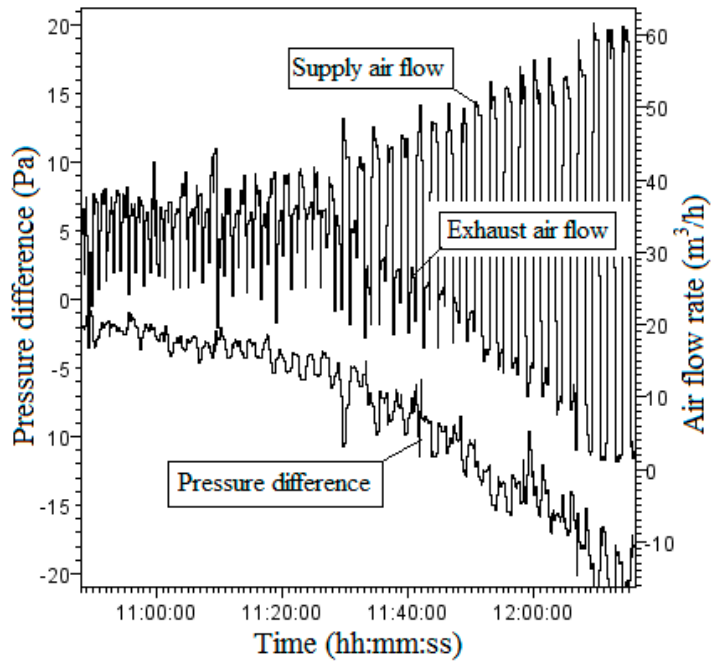

(a)

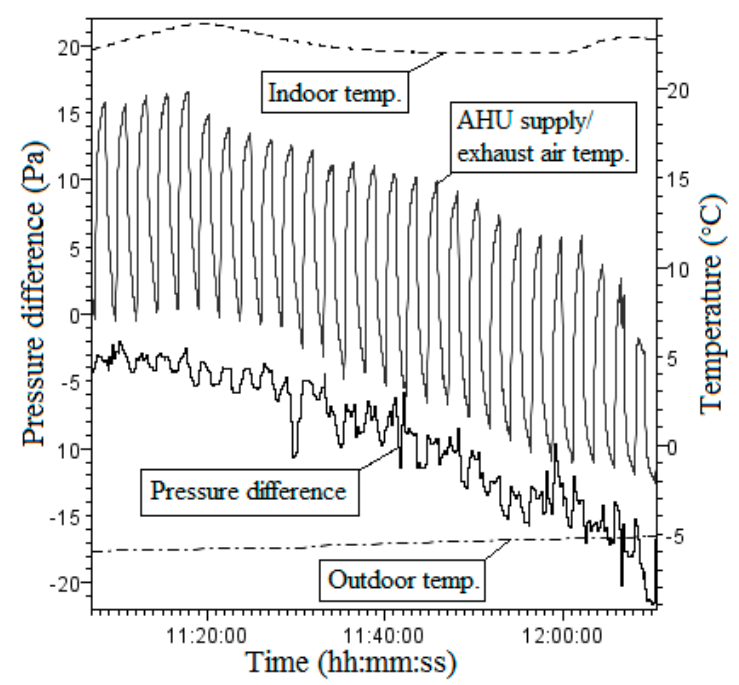

(b)

Figure 9. The results of the laboratory measurements of performance of the room unit with regenerative HEX at 75\% fan power: (a) Pressure difference and air flows; (b) pressure difference and supply/exhaust air temperature.

The fan performance curves were constructed for the fan speed levels of $25 \%, 50 \%, 75 \%$, and $100 \%$ (see Figure 10a). The fan performance curves show how the supply and extract airflows of the ventilation units are related to the in-and outdoor pressure difference. It is also possible to present how the pressure difference is related to the temperature efficiency of studied ventilation units (see Figure 10b). The results indicate that if the pressure difference rises then the temperature efficiency decreases. The same trend appears for all tested fan speeds. For example, in case the $50 \%$ speed level, the temperature efficiency is over 0.5 if the pressure difference is smaller than $4 \mathrm{~Pa}$.

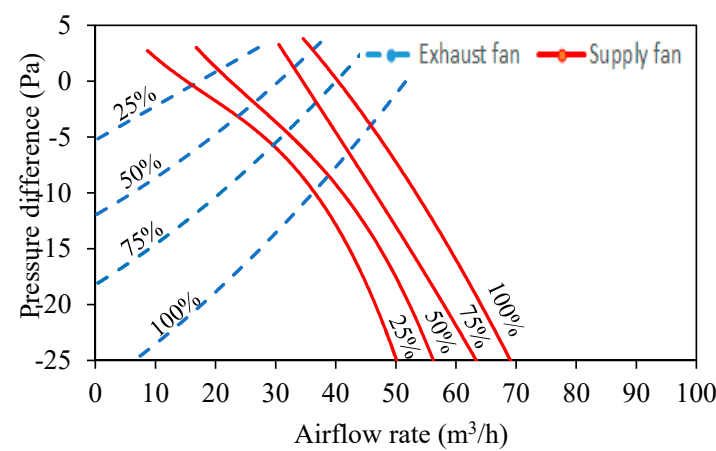

(a)

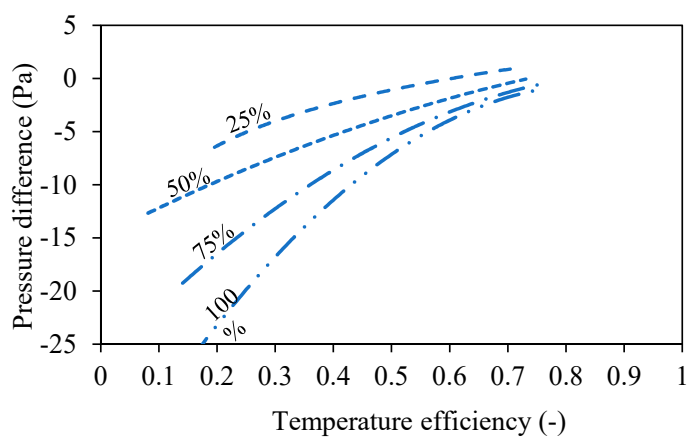

(b)

Figure 10. (a) Measurement based fan performance curves of room-based ventilation units with ceramic regenerative HEX; (b) measurement based temperature efficiencies of room-based ventilation units with ceramic regenerative HEX.

The fan performance curves and temperature efficiency graphs were also constructed for the ventilation units with recuperative HEX (see Figure 11a,b). The fan performance curves were constructed for the fan speed levels $25 \%, 50 \%, 75 \%$, and $100 \%$. Compared to the ventilation units with regenerative HEX, the units with recuperative can perform effectively in case of higher pressure differences between indoor and outdoor air. At the same time, if the pressure difference is $-20 \mathrm{~Pa}$ at fan speed level $50 \%$, the supply airflow is about $15 \%$ higher than exhaust airflow. The temperature efficiency of ventilation units with recuperative HEX is presented in Figure 11b. Compared to units with regenerative HEX, the temperature efficiency of studied ventilation units is significantly better at 
higher pressure difference conditions. The pressure difference influences the temperature efficiency the most in lower fan speed levels.

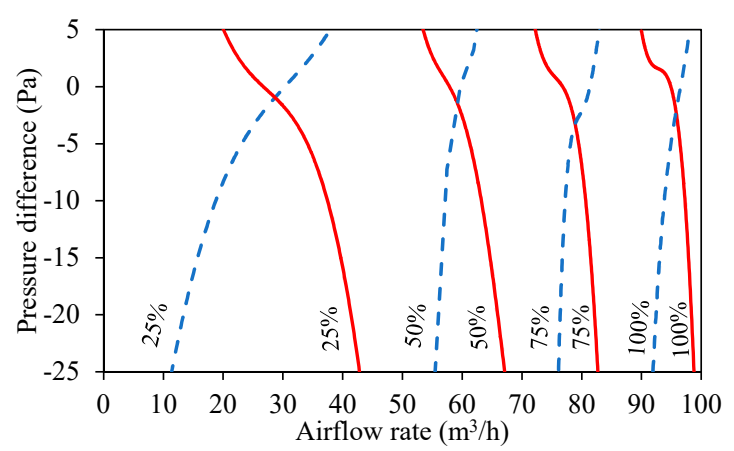

(a)

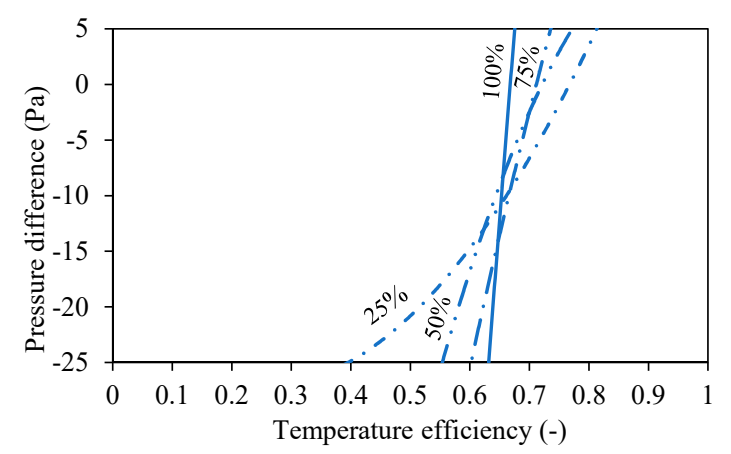

(b)

Figure 11. (a) Measurement based fan performance curves of room-based ventilation units with recuperative cross-flow plate HEX; (b) Measurement based temperature efficiencies of room-based ventilation units with recuperative cross-flow plate HEX.

\subsection{Simulation Results}

The simulation results achieved in the validation process are in good concordance with the field measurements (see Figure 12a), considering the fact that approximate wind pressure coefficients, performance of natural exhaust ventilation and wind data from an off-site weather station was used. The whole-year simulation results are presented in Figure 12b. The results show that the whole building is under negative pressure for $63 \%$ of the year ( $5521 \mathrm{~h}$ per year). In the first-floor apartments, the pressure difference is below $-10 \mathrm{~Pa}$ for $22 \%$ (1927 h per year) and lower than $-20 \mathrm{~Pa}$ for $2 \%$ of the year (180 $\mathrm{h}$ per year). The pressure difference across the exterior wall during the heating season in the 5-story building can be as high as $-30 \mathrm{~Pa}$ on the first floor, $-20 \mathrm{~Pa}$ on the third floor and $-15 \mathrm{~Pa}$ on the fifth floor. Although the performed whole-year simulations has been done according to only one building and some simplifications have been done during the simulation process, the results confirm the fact that room based ventilation systems in 5-story buildings have to cope with the pressure difference which is more than $-20 \mathrm{~Pa}$.

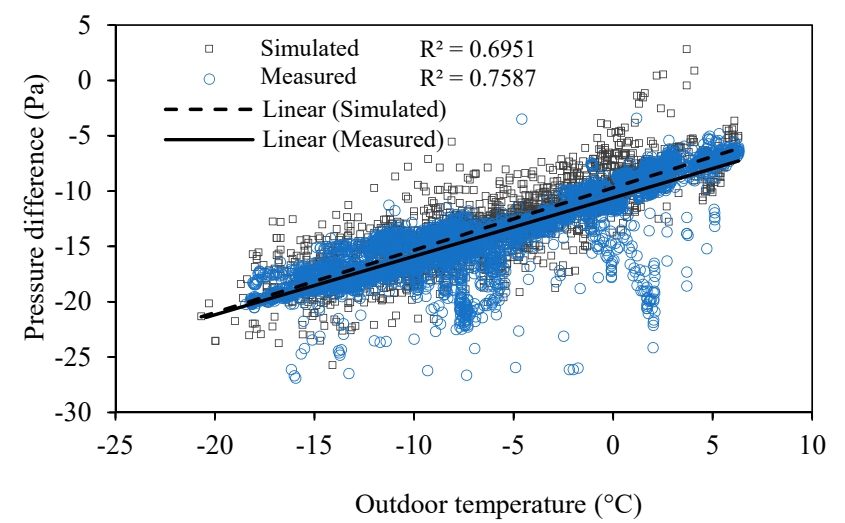

(a)

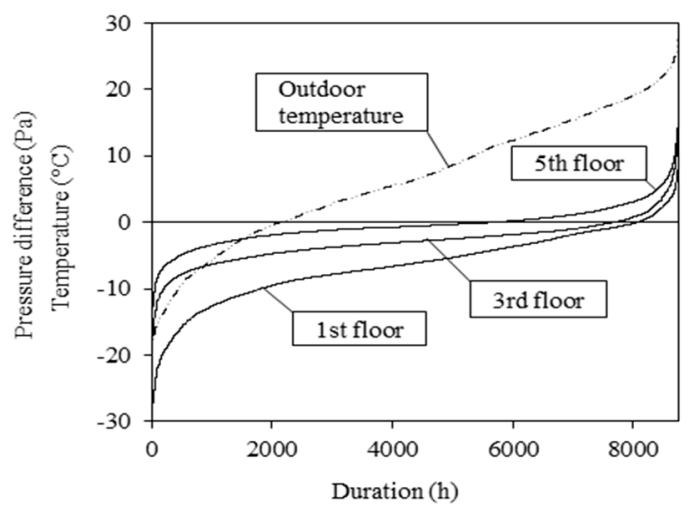

(b)

Figure 12. (a) Dependence between measured and simulated indoor and outdoor pressure differences on the indoor-outdoor temperature difference in the first-floor apartment. (b) The outdoor temperature and simulated whole-year pressure difference in the top, middle and bottom floor apartments of the 5-story apartment building.

The simulations of the single room ventilation units with the regenerative ceramic HEX were made using the same calibrated model of 5-story apartment building which was used in whole-year 
pressure difference simulations. The performance data of the fans and HEX has been taken from the results of laboratory tests that are described in pt. 3.2. As the studied ventilation units have to ensure the low noise level in living room and bedroom, the unit can only work in 30-50\% speed level. An example of supply temperature and airflow rates simulation results of the ventilation unit with ceramic HEX, located in first floor, are shown as duration curves in Figure 13. During heating season, supply air temperature is relatively close to the outdoor temperature (Figure 13a) and that supply airflow rate is much higher than exhaust airflow rate (Figure 13b).

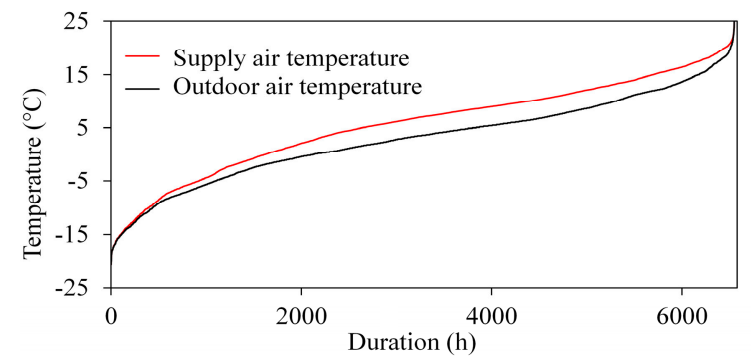

(a)

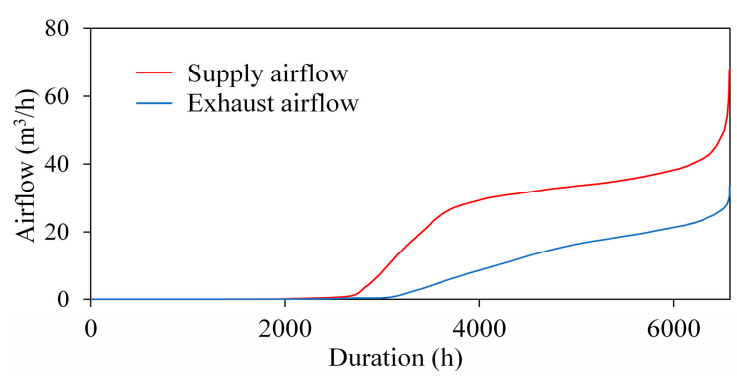

(b)

Figure 13. (a) Simulated supply air temperature and (b) airflow rates duration curves for ventilation unit with regenerative HEX during heating period in 1st floor apartment (September-May).

\section{Discussion}

The field measurements show that the pressure difference between the indoor and outdoor air in the bottom floor apartment depends heavily on the outdoor temperature, indicating the influence of the stack effect, whereas on the top floor, due to the smaller height of the exhaust ventilation shaft, the dependence is weak. Similar results have been also shown in other studies [50,51]. Kiviste and Vinha [50] have studied different Finish buildings and found that in some cases there can be large underpressure conditions $(<-15 \mathrm{~Pa})$ between in-and outdoor environments. Kalamees et al. [28] showed that in most critical cases, the air pressure across the building envelope may rise up to $30 \mathrm{~Pa}$ and the main reason for that is airtight building envelope with unbalanced ventilation. This study confirms that in renovated 5-stories apartment buildings with natural exhaust ventilation, the pressure difference across the building envelope can rise up to 20-30 Pa. Analyzing the fan performance of room-based ventilation units with regenerative HEX, it can be concluded that the pressure differences over the envelope were caused by the natural ventilation and density differences between the indoor and outdoor air. The room-based ventilation units itself did not play a significant role to increase the pressure drop across the building envelope.

During the analysis of the pressure difference measurement results and calibrating the model, the occasional peaks toward zero-pressure difference (see Figure 8a). These peaks are most likely caused by opening the windows or external doors to the balcony or staircase, the peaks and periods toward greater difference indicate the wind-induced effect. As the kitchen hoods and exhaust fans were installed in some apartments of studied building, the peaks can also be caused by these components of mechanical ventilation. Pressure difference caused by wind can be dominant also for longer periods. Although the wind-induced component varies in a wide range and depends on multiple variables, its contribution to the pressure conditions can be considerable, and thus special attention needs to be paid to buildings in wind exposed locations. Kalamees et al. [28] found that wind primarily influence the peak air pressure values and comparing the average values, the influence of wind is small. Despite the wind effect and other uncertainties during the pressure measuring and model compilation, we can see that dependence between measured and simulated indoor and outdoor pressure differences is quite strong (see Figure 12a). In the first floor the value of linear correlation coefficient of simulated data is 0.6951 and the correlation coefficient of measured data is 0.7587 . The values of correlation 
coefficients, together with the similarity in results of simulation and measurement indicates that the calibration of the model was successful.

The laboratory measurement results of the studied room-based ventilation units show that supply and extract airflows are equal only at very low pressure differences. The greater the gap, the more the airflows differ. It can be seen, that the unit with plate HEX is performing considerably better, mainly due to centrifugal fans, but also because of the constant airflows. In case of the unit with regenerative HEX, the pressure difference is causing low-pressure axial fan to perform poorly: smaller volumes of exhaust air to flow through the unit during exhaust cycle, lowering the heat quantity accumulated in the HEX and leaving the outdoor air heating insufficient. The effect escalates with lower outdoor temperatures and higher pressure differences, in which case the heat transfer in the unit degrades and larger volumes of cold air are entering the ventilated space. It means that the pressure difference across the building envelope is closely related to the temperature efficiency of studied ventilation systems.

The performance of room-based ventilation units have also been monitored in previous studies. Smith et al. have developed the ventilation units with plastic rotary HEX [25,44]. They have made airflow measurements of the tested units using the tracer gas method. The main conclusion of this study was that the temperature efficiency of studied unit on equal supply and exhaust airflows is about $0.83-0.84$ [25]. As these tests were not performed in different indoor and outdoor pressure conditions, it is not possible to make the conclusion, how these units would perform in apartment buildings in cold climate region.

Based on the simulation results, the pressure difference across the exterior wall during the heating season in a five-story building can be as high as $-30 \mathrm{~Pa}$ on the first floor, $-20 \mathrm{~Pa}$ on the third floor, and $-15 \mathrm{~Pa}$ on the fifth floor. Comparing the simulated pressure conditions and the measured characteristics of the ventilation unit, poor performance of the unit can be expected. The simulation results of room-based units with regenerative HEX show that during heating season, supply air temperature is relatively close to the outdoor temperature and that supply airflow rate is much higher than exhaust airflow rate. At the same time the unit with recuperative HEX can ensure the temperature efficiency of the unit over 0.5 even under negative pressure as high as $-25 \mathrm{~Pa}$, making it possible to use the device in first floor apartments.

Several studies have shown that room-based ventilation units in Estonian apartment buildings are not ensuring the necessary air change rate [3,7,18]. Mikola et al. [3] point out that as these room units generate high sound power level, people switched ventilation units to the $30 \%$ of the maximum airflow. If tested room units with regenerative HEX work at 30\% speed level and the pressure difference across the building envelope is $-8 \mathrm{~Pa}$ then the supply airflow is 2 times higher than the exhaust airflow from the room. Mikola et al. [3] also measured the air change rate in apartments with regenerative room-based units. According to the measurements results, the average air exchange rate was $0.18 \mathrm{~h}^{-1}$ and the average airflow per surface area of an apartment was $0.12 \mathrm{~L} /\left(\mathrm{s}^{*} \mathrm{~m}^{2}\right)$. According to the indoor climate category III, the general ventilation airflow in old apartments should be at least $0.35 \mathrm{~L} /\left(\mathrm{s}^{*} \mathrm{~m}^{2}\right)$ or $0.5 \mathrm{~h}^{-1}$ and airflow in living rooms and bedrooms should be at least $0.6 \mathrm{~L} /\left(\mathrm{s}^{*} \mathrm{~m}^{2}\right)$ or $4 \mathrm{~L} /\left(\mathrm{s}^{*}\right.$ person). The indoor climate category III requirements for the air change rate were also a minimum requirement to apply for the renovation grant. The air exchange rate met the requirements of III class in $6 \%$ of the apartments with room-based ventilation units [3]. In rest of the apartments, the minimum requirement of renovation grant scheme, was not ensured. It can be concluded, that the measured room-based ventilation renovation solution in apartment buildings does not ensure the necessary air change rate.

In case of both studied room-based ventilation units, the only possible to protect the HEX from freezing in cold climate is to reduce the supply airflow. As proven in this study, the exhaust airflow can be very small if the air pressure difference across the building envelope is high. That is the reason why there is high risk of ice formation in HEX, which complicates using these units in rooms with high humidity. The freezing process of HEXs of room-based units is not analyzed in detail during this study, so it would be worth to study this in future. 
Based on previous studies $[1,8,40]$ in Estonian climate, the following ventilation renovation solutions have performed better than room ventilation units:

- Apartment based supply and exhaust ventilation system with heat recovery, with unit located in apartment, in corridor or staircase.

- Centralized supply and exhaust ventilation system with heat recovery, with unit located on roof, pipes located in external wall or in apartment.

- Centralized exhaust ventilation system with fresh air radiators and heat pump heat recovery.

\section{Conclusions}

In this study, field measurements of pressure difference across the building envelope were carried out during a three-month period of the heating season in a fully renovated five-story apartment building. The results were used to validate the IDA-ICE whole building simulation model allowing to simulate hourly whole-year pressure conditions and airflows. Considering the measured and simulated pressure conditions, the performance of two different single room ventilation units was studied: one of the units was a device with a recuperative cross-flow plate HEX and two centrifugal fans and another with a regenerative ceramic HEX and an axial fan. The units were tested in TalTech technological facility, where supply and exhaust temperatures and airflow rates were measured under changing pressure conditions and different fan speeds. Fan and heat recovery efficiency curves were created and modelled in IDA-ICE for whole-year performance assessment.

In both cases of the studied ventilation units, pressure differences generated large differences in the supply and exhaust air flow rates. Because of the higher pressure rise, the airflow balance difference was much smaller in case of the unit with centrifugal fans compared to the unit with axial fan. This resulted in the smaller change in heat recovery efficiency of the recuperative HEX, compared to the regenerative HEX case which practically lost its heat recovery because of dominating stack effect pressure.

The simulation results show, that in cold periods, apartments in the first floor can be under negative pressure as high as $-20 \mathrm{~Pa}$ for longer periods of time. In ventilation system planning, values of $-10 \mathrm{~Pa}$ in fifth floor, $-15 \mathrm{~Pa}$ in third floor and $-20 \mathrm{~Pa}$ in first floor apartments can be recommended to be used as design values for ventilation units. The simulation results of single room units with regenerative HEX show that during heating season, supply air temperature was close to the outdoor temperature and that supply airflow rate was much higher than exhaust airflow rate, showing that the unit operated as air intake. Due to the differences in supply and exhaust airflows, there is a risk for freezing the heat exchanger, which excludes using studied ventilation units in rooms with high humidity.

The laboratory measurement results confirmed, that the axial fan used in the ventilation unit was not capable to work in typical pressure conditions occurring in multi-story building in cold periods, in order to achieve sufficient air change rate, heat recovery and supply air temperature, with noise levels under acceptable limits. In the case of the unit with recuperative HEX, under the same circumstances, the temperature efficiency of the unit remained higher than 0.5 even under negative pressure as high as $-25 \mathrm{~Pa}$, making it possible to use the device in first floor apartments.

Author Contributions: The laboratory and field measurements were performed by A.M. and R.S. Analyses of the measured data was carried out by A.M. and R.S. The simulation model was calibrated by R.S. The research principles and methods of the study were developed by A.M., R.S. and J.K.

Funding: This research was supported by the Estonian Centre of Excellence in Zero Energy and Resource Efficient Smart Buildings and Districts, ZEBE, grant 2014-2020.4.01.15-0016 funded by the European Regional Development Fund.

Acknowledgments: Authors would also like to thank Fund Kredex for cooperation of our research work.

Conflicts of Interest: The authors declare no conflict of interest. 


\section{References}

1. Kuusk, K.; Kalamees, T.; Maivel, M. Cost effectiveness of energy performance improvements in Estonian brick apartment buildings. Energy Build. 2014, 77, 313-322. [CrossRef]

2. Directive (EU) 2018/844 of the European Parliament and of the Council of 30 May 2018 Amending Directive 2010/31/EU on the Energy Performance of Buildings and Directive 2012/27/EU on Energy Efficiency. Available online: https://eur-lex.europa.eu/legal-content/EN/TXT/?uri=OJ:L:2018:156:TOC (accessed on 30 April 2019).

3. Mikola, A.; Kõiv, T.-A.; Tennokese, K. Improving the indoor climate and energy saving in renovated apartment buildings in Estonia. In Proceedings of the 12th REHVA World Congress CLIMA 2016, Aalborg, Denmark, 22-25 May 2016.

4. Mikola, A.; Kõiv, T.-A.; Kalamees, T. Quality of ventilation systems in residential buildings: Status and perspectives in Estonia. In Proceedings of the International Workshop Securing the Quality of Ventilation Systems in Residential Buildings: Status and Perspectives, Brussels, Belgium, 18-19 March 2013.

5. Kalamees, T.; Kuusk, K.; Arumägi, E.; Ilomets, S.; Maivel, M. The analysis of measured energy consumption in apartment buildings in Estonia. In Proceedings of the IEA Annex 55 (RAP-RETRO), Working Meeting, Vienna, Austria, 23-25 April 2012.

6. Kurnitski, J.; Kuusk, K.; Tark, T.; Uutar, A.; Kalamees, T.; Pikas, E. Energy and investment intensity of integrated renovation and 2030 cost optimal savings. Energy Build. 2014, 75, 51-59. [CrossRef]

7. Hamburg, A.; Kalamees, T. The Influence of Energy Renovation on the Change of Indoor Temperature and Energy Use. Energies 2018, 11, 3179. [CrossRef]

8. Kuusk, K.; Kalamees, T. Estonian Grant Scheme for Renovating Apartment Buildings. Energy Procedia 2016, 96, 628-637. [CrossRef]

9. Paap, L.; Mikola, A.; Kõiv, T.-A.; Kalamees, T. Airtightness and ventilation of new Estonian apartments constructed 2001-2010. In Proceedings of the Joint Conference 33rd AIVC Conference and 2nd TightVent Conference Optimising Ventilative Cooling and Airtightness for [Nearly] Zero-Energy Buildings, IAQ and Comfort, Copenhagen, Denmark, 10-11 October 2012.

10. Armstrong, P.; Dirks, J.; Klevgard, L.; Matrosov, Y.; Olkinuora, J. Infiltration and Ventilation in Russian Multi-Family Buildings. In Proceedings of the ACEEE Summer Study on Energy Efficiency in Buildings, Residential Buildings: Technologies, Design, and Performance Analysis, Pacific Grove, CA, USA, 25-31 August 1996.

11. Wargocki, P.; Sundell, J.; Bischof, W.; Brundrett, G.; Fanger, P.; Gyntelberg, F.; Hanssen, S.; Harrison, P.; Pickering, A.; Seppanen, O.; et al. Ventilation and health in non-industrial indoor environments: Report from a European Multidisciplinary Scientific Consensus Meeting (EUROVEN). Indoor Air 2002, 12, $113-128$. [CrossRef] [PubMed]

12. Iversen, M.; Bach, E.; Lundqvist, G. Health and comfort changes among tenants after retrofitting of their housing. Environ. Int. 1986, 12, 161-166. [CrossRef]

13. Menzies, R.; Tamblyn, R.; Farant, J.; Hanley, J.; Nunes, F.; Tamblyn, R. The Effect of Varying Levels of Outdoor-Air Supply on the Symptoms of Sick Building Syndrome. N. Engl. J. Med. 1993, 328, 821-827. [CrossRef] [PubMed]

14. Seppanen, O.; Fisk, W.; Mendell, M. Association of Ventilation Rates and $\mathrm{CO}_{2}$ Concentrations with Health andOther Responses in Commercial and Institutional Buildings. Indoor Air 1999, 9, 226-252. [CrossRef]

15. Ucci, M.; Ridley, I.; Pretlove, S.; Davies, M.; Mumovic, D.; Oreszczyn, T.; McCarthy, M.; Singh, J. Ventilation rates and moisture-related allergens in UK dwellings. In Proceedings of the 2nd WHO International Housing and Health Symposium, Vilnius, Lithuania, 29 September-1 October 2004.

16. Ruotsalainen, R.; Jaakkola1, J.; Ronnberg, R.; Majanen, A.; Seppanen, O. Symptoms and Perceived Indoor Air Quality among Occupants of Houses and Apartments with Different Ventilation Systems. Indoor Air 1991, 1, 428-438. [CrossRef]

17. Noris, F.; Adamkiewicz, G.; Delp, W.; Hotchi, T.; Russell, M.; Singer, B.; Spears, M.; Vermeer, K.; Fisk, W. Indoor environmental quality benefits of apartment energy retrofits. Build. Environ. 2013, 68, 170-178. [CrossRef] 
18. Hamburg, A.; Kalamees, T. Improving the indoor climate and energy saving in renovated apartment buildings in Estonia. In Proceedings of the 9th International Cold Climate HVAC 2018, Kiruna, Sweden, 12-15 March 2018.

19. Jokisalo, J.; Kurnitski, J.; Korpi, M.; Kalamees, T.; Vinha, J. Building leakage, infiltration, and energy performance analyses for Finnish detached houses. Build. Environ. 2009, 44, 377-387. [CrossRef]

20. Papakostas, K.; Kiosis, G. Heat recovery in an air-conditioning system with air-to-air HEX. Int. J. Sustain. Energy 2014, 34, 221-231. [CrossRef]

21. El Fouih, Y.; Stabat, P.; Rivière, P.; Hoang, P.; Archambault, V. Adequacy of air-to-air heat recovery ventilation system applied in low energy buildings. Energy Build. 2012, 54, 29-39. [CrossRef]

22. Merzkirch, A.; Maas, S.; Scholzen, F.; Waldmann, D. Field tests of centralized and decentralized ventilation units in residential buildings-Specific fan power, heat recovery efficiency, shortcuts and volume flow unbalances. Energy Build. 2016, 116, 376-383. [CrossRef]

23. Kim, M.; Baldini, L. Energy analysis of a decentralized ventilation system compared with centralized ventilation systems in European climates: Based on review of analyses. Energy Build. 2016, 111, 424-433. [CrossRef]

24. Santos, H.; Leal, V. Energy vs. ventilation rate in buildings: A comprehensive scenario-based assessment in the European context. Energy Build. 2012, 54, 111-121. [CrossRef]

25. Smith, K.; Svendsen, S. Development of a plastic rotary HEX for room-based ventilation in existing apartments. Energy Build. 2015, 107, 1-10. [CrossRef]

26. Manz, H.; Huber, H.; Schälin, A.; Weber, A.; Ferrazzini, M.; Studer, M. Performance of single room ventilation units with recuperative or regenerative heat recovery. Energy Build. 2000, 31, 37-47. [CrossRef]

27. Liu, J.; Li, W.; Liu, J.; Wang, B. Efficiency of energy recovery ventilator with various weathers and its energy saving performance in a residential apartment. Energy Build. 2010, 42, 43-49. [CrossRef]

28. Hosseini, S.M.; Carli, R.; Dotoli, M. Model Predictive Control for Real-Time Residential Energy Scheduling under Uncertainties. In Proceedings of the IEEE International Conference on Systems, Man, and Cybernetics (SMC), Miyazaki, Japan, 7-10 October 2018; pp. 1386-1391.

29. Chen, J.; Augenbroe, G.; Song, X. Lighted-weighted model predictive control for hybrid ventilation operation based on clusters of neural network models. Autom. Constr. 2018, 89, 250-265. [CrossRef]

30. Kalamees, T.; Kurnitski, J.; Jokisalo, J.; Eskola, L.; Jokiranta, K.; Vinha, J. Measured and simulated air pressure conditions in Finnish residential buildings. Build. Serv. Eng. Res. Technol. 2010, 31, 177-190. [CrossRef]

31. Khoukhi, M.; Al-Maqbali, A. Stack Pressure and Airflow Movement in High and Medium Rise buildings. Energy Procedia 2011, 6, 422-431. [CrossRef]

32. Khoukhi, M.; Yoshino, H.; Liu, J. The effect of the wind speed velocity on the stack pressure in medium-rise buildings in cold region of China. Build. Environ. 2007, 42, 1081-1088. [CrossRef]

33. Acred, A.; Hunt, G. Multiple Flow Regimes in Stack Ventilation of Multi-Story Atrium Buildings. Int. J. Vent. 2013, 12, 31-40. [CrossRef]

34. Tovar, T.; Garrido, C. Stack-Driven Ventilation in Two Interconnected Rooms Sharing a Single Opening and Connected to the Exterior by a Lower Vent. Int. J. Vent. 2010, 9, 211-226. [CrossRef]

35. Kalamees, T.; Arumägi, E.; Tähiste, M. Air tightness of apartment buildings in Estonia. In Proceedings of the 4th International Symposium on Building and Ductwork Air Tightness (BUILDAIR)/30th AIVC Conference: Trends in High Performance Buildings and the Role of Ventilation, Berlin, Germany, 1-2 October 2009.

36. Gładyszewska-Fiedoruk, K.; Gajewski, A. Effect of wind on stack ventilation performance. Energy Build. 2012, 51, 242-247. [CrossRef]

37. Etheridge, D. Wind Turbulence and Multiple Solutions for Opposing Wind and Buoyancy. Int. J. Vent. 2009, 7, 309-320. [CrossRef]

38. Kalamees, T.; Korpi, M.; Eskola, L.; Kurnitski, J.; Vinha, J. The distribution of the air leakage places and thermal bridges in Finnish detached houses and apartment buildings. In Proceedings of the 8th Symposium on Building Physics in the Nordic Countries: Dept. of Civil Engineering, Copenhagen, Denmark, 16-18 June 2008.

39. Jo, J.; Lim, J.; Song, S.; Yeo, M.; Kim, K. Characteristics of pressure distribution and solution to the problems caused by stack effect in high-rise residential buildings. Build. Environ. 2007, 42, 263-277. [CrossRef]

40. Mikola, A.; Kalamees, T.; Kõiv, T.-A. Performance of ventilation in Estonian apartment buildings. Energy Procedia 2017, 132, 963-968. [CrossRef] 
41. Kalamees, T.; Kurnitski, J. Estonian Test Reference Year for Energy Calculations. Proc. Est. Acad. Sci. Eng. 2006, 12, 40-58.

42. Kuusk, K.; Kalamees, T.; Link, S.; Ilomets, S.; Mikola, A. Case-study analysis of concrete large-panel apartment building at pre- and post low-budget energy-renovation. J. Civ. Eng. Manag. 2016, 23, 67-75. [CrossRef]

43. ASHRAE. Airflow around buildings. In Book 1993 ASHRAE Handbook-Fundamentals; American Society of Heating, Refrigerating and Air Conditioning Engineers: Atlanta, GA, USA, 1993.

44. Smith, K.; Svendsen, S. The effect of a rotary HEX in room-based ventilation on indoor humidity in existing apartments in temperate climates. Energy Build. 2016, 116, 349-361. [CrossRef]

45. Peng, X.; Yang, L.; Gavanski, E.; Gurley, K.; Prevatt, D. A comparison of methods to estimate peak wind loads on buildings. J. Wind Eng. Ind. Aerodyn. 2014, 126, 11-23. [CrossRef]

46. Montazeri, H.; Blocken, B. CFD simulation of wind-induced pressure coefficients on buildings with and without balconies: Validation and sensitivity analysis. Build. Environ. 2013, 60, 137-149. [CrossRef]

47. Grosso, M. Wind pressure distribution around buildings: A parametrical model. Energy Build. 1992, 18, 101-131. [CrossRef]

48. Sherman, M.H.; Grimsrud, D. Infiltration-pressurization correlation: Simplified physical modeling. ASHRAE Trans. 1980, 86, 778-807.

49. Modera, M.P.; Sherman, M.H.; Grimsrud, D.T. A Predictive Air Infiltration Model-Long-Term Field Test Validation. In Proceedings of the Semi-annual meeting of the American Society of Heating, Refrigerating, and Air Conditioning Engineers, Houston, TX, USA, 24 January 1982; Available online: https://www.osti. gov/biblio/6285265 (accessed on 4 March 2019).

50. Kiviste, M.; Vinha, J. Air pressure difference measurements in Finnish municipal service buildings. Energy Procedia 2017, 132, 879-884. [CrossRef]

51. Leivo, V.; Kiviste, M.; Aaltonen, A.; Turunen, M.; Haverinen-Shaughnessy, U. Air Pressure Difference between Indoor and Outdoor or Staircase in Multi-family Buildings with Exhaust Ventilation System in Finland. Energy Procedia 2015, 78, 1218-1223. [CrossRef]

(C) 2019 by the authors. Licensee MDPI, Basel, Switzerland. This article is an open access article distributed under the terms and conditions of the Creative Commons Attribution (CC BY) license (http://creativecommons.org/licenses/by/4.0/). 